Www.jmscr.igmpublication.org

Index Copernicus Value: 79.54

ISSN (e)-2347-176x ISSN (p) 2455-0450

crossrefDOI: https://dx.doi.org/10.18535/jmscr/v7i2.145

\title{
Caregiver burden of elderly psychiatric and medically ill patients: A comparative study
}

\author{
Authors \\ Vishal Sinha, Zeeshan Anwar, Sayantanava Mitra, Narveer Yadav \\ Department of Psychiatry, SN Medical College, Agra, UP, India
}

\begin{abstract}
Caregivers of elderly patients suffering from chronic illnesses are at increased risk of health problems themselves. In India, caregivers of elderly patients are usually close family members. The aim of the study was to assess and compare the burden on caregivers of elderly medical and psychiatric patients. A total of 60 elderly patients and their caregivers (30 patients and 30 caregivers in each group) were included in the study. Burden on the caregivers of elderly psychiatric patients was significantly more than that of caregivers of elderly medical patients and worsens with the deterioration of general health and quality of life of elderly patients and with increasing age and duration of care giving. Proper intervention to reduce the burden among the caregivers of elderly patients, particularly psychiatric patients, should be routinely incorporated for the betterment of both the patients and caregivers.

Keywords: caregiver burden, elderly, psychiatric.
\end{abstract}

\section{Introduction}

In most countries, the proportion of people aged over 60 years is growing faster than any other age group and by the year 2020, world's elderly population is expected to be 2 billion, most of which will be living in developing countries ${ }^{1}$. India is an ageing country as in 2001 elderly people (aged 60 years or above) accounted for $7.4 \%$ (71 million) of total population and is expected to reach 173 million by $2026^{2}$. This poses a significant burden on resources of country as proportion of dependent population is increasing and working population is decreasing. More than $20 \%$ of elderly suffer from a mental or neurological disorder and $6.6 \%$ of all disability among over $60 \mathrm{~s}$ is attributed to neurological and mental disorders. The most common neuropsychiatric disorders in this age group are dementia and depression followed by Anxiety disorders $(3.8 \%) \&$ substance use problems (1\%) and around a quarter of deaths from self-harm are among those aged 60 or above ${ }^{3}$.

Caregiver may be defined as a person responsible for meeting both physical and psychological requirements of the dependent individuals ${ }^{4}$. Caregiver burden is a state resulting from providing the necessary care to an impaired older adult \& that threatens either the physical or psychological wellbeing of the caregiver ${ }^{5,6}$. In developing countries like India most of the care for the elderly is provided by informal caregivers, most of whom are family.Grad and Sainbury first acknowledged the caregiver burden in psychiatric patients residing at home ${ }^{7}$. Providing care to an 
elderly often restricts the personal, social, and occupational life of the caregiver \& has been identified as a chronic stressor that places caregivers at risk for physical and emotional problems $^{8}$. Caregivers have less time to spend with friends, fulfill family obligations, or to pursue leisure activities ${ }^{9}$. Furthermore, caregivers are often faced with difficult care giving tasks while faced with verbal, physical aggression, confusion and behavior problems of demented care recipients ${ }^{10}$.

Caregivers frequently suffer from depression, have poorer quality of life, report more physical and psychological symptoms, and use more frequent prescription medications \& healthcare services than comparable non-caregivers ${ }^{11,12}$. But only when problems \& difficulties experienced by caregiver reaches a point where signs of burnout are clearly apparent and do not allow the things to run comfortably for both caregiver and elderly only then they are given proper consideration.

Previous research has shown conflicting results regarding the predictors of caregiver burden, particularly the one related to degree of disability of care recipients causing functional impairment in the basic daily activities, duration of time spent as caregivers $\&$ relationship between the caregiver and the care-recipient. While some studies shows a significant relationship between them, other found no or weak association. Caregiver burden correlate with associated depression and behavioral problems in dementia patients ${ }^{13-16}$.It is also known that caregivers of mentally ill patients experience higher level of stress than caregivers of patients with chronic medical illness ${ }^{4}$.

Care of elderly psychiatric patient is a real challenge for caregivers and the needs of caregivers are often neglected, leading to impairment of their quality of life as well as that of care recipients. Unfortunately only meager of Indian studies have investigated the interactions between patient characteristics, caregiver attributes and support mechanisms, which eventually determine burden of care experienced by caregivers. So, it is still a thrust area of research, as there is paucity of data comparing the burden experienced by caregivers of elderly psychiatric and medically ill patients. So the present study is an attempt to provide a better insight to the caregiver burden of elderly patients, so that it can be detected and managed at early stages.

\section{Methodology}

A cross sectional study was conducted in a Medical College of northern India and all the elderly psychiatric patients aged more than 60 years of age and their primary caregivers (of at least 18 years of age, living with the elderly patient, providing care and responsible for their day to day life decisions for a minimum of 1 year duration and are themselves not suffering from any major medical or psychiatric illness) attending psychiatric, who agreed to give a written informed consent to participate in the study were included. Matched controls having no documented (previous \& current) mental illness, and suffering from a chronic medical illness, attending medicine OPD along with their primary caregivers were also included. Only subjects who were in a physical condition to carry out the interview were selected. All the elderly patients and their caregivers were assessed using pre- structured socio demographic parameters, detailed history and general examination, mental state examination, vitals, WHO QOL (Quality Of Life) $-\mathrm{BREF}^{17}$, General Health Questionnaire (GHQ)$30^{18}$. In addition to that caregivers were also assessed using Zarit's Burden Interview (ZBI) ${ }^{19}$. 


\section{Results}

Table 1: socio-demographic characteristics of elderly patients

\begin{tabular}{|c|c|c|c|c|c|c|c|}
\hline SDP elderly & \multirow{2}{*}{ Frequency } & \multirow{2}{*}{ Percentage } & \multicolumn{2}{|c|}{ Illness } & \multirow{2}{*}{ Chi-square } & \multirow[t]{2}{*}{$\mathrm{df}$} & \multirow[t]{2}{*}{$\mathrm{p}$-value } \\
\hline Age & & & Psychiatric & Medical & & & \\
\hline $60-67$ & 30 & 50 & 16 & 14 & \multirow[b]{3}{*}{3.15} & \multirow[b]{3}{*}{2} & \multirow[b]{3}{*}{0.854} \\
\hline $68-75$ & 22 & 36.7 & 10 & 12 & & & \\
\hline$\geq 76$ & 8 & 13.3 & 4 & 4 & & & \\
\hline \multicolumn{8}{|c|}{$\begin{array}{l}\text { Mean age of elderly psychiatric patients: } 68.16 \pm 5.88 \text { years } \\
\text { Mean age of elderly medical patients: } 68.73 \pm 5.92 \text { years }\end{array}$} \\
\hline \multicolumn{5}{|c|}{\begin{tabular}{l|l} 
Sex & \\
\end{tabular}} & \multirow[b]{3}{*}{2.70} & \multirow[b]{3}{*}{1} & \multirow[b]{3}{*}{0.10} \\
\hline Male & 40 & 66.67 & 23 & 17 & & & \\
\hline Female & 20 & 33.3 & 7 & 13 & & & \\
\hline \multicolumn{5}{|l|}{ Marital status } & \multirow[b]{5}{*}{3.06} & \multirow[b]{5}{*}{3} & \multirow[b]{5}{*}{0.382} \\
\hline Single & 2 & 3.33 & 0 & 2 & & & \\
\hline Married & 40 & 66.67 & 19 & 21 & & & \\
\hline Widow/widower & 11 & 18.3 & 7 & 4 & & & \\
\hline Divorced/separated & 7 & 11.6 & 4 & 3 & & & \\
\hline
\end{tabular}

Table 2: socio-demographic characteristics of caregivers of elderly patients

\begin{tabular}{|c|c|c|c|c|c|c|c|}
\hline SDP caregiver & \multirow{2}{*}{ Frequency } & \multirow{2}{*}{ Percentage } & \multicolumn{2}{|c|}{ Illness } & \multirow{2}{*}{ Chi-square } & \multirow{2}{*}{$\mathrm{df}$} & \multirow{2}{*}{$\begin{array}{c}\text { p- } \\
\text { value }\end{array}$} \\
\hline Age & & & Psychiatric & Medical & & & \\
\hline $18-30$ & 2 & 3.33 & 1 & 1 & \multirow{5}{*}{3.723} & \multirow{5}{*}{4} & \multirow{5}{*}{0.445} \\
\hline $31-40$ & 20 & 33.33 & 12 & 8 & & & \\
\hline $41-50$ & 15 & 25 & 9 & 6 & & & \\
\hline $51-60$ & 13 & 21.67 & 4 & 9 & & & \\
\hline$\geq 61$ & 10 & 16.66 & 4 & 6 & & & \\
\hline \multicolumn{8}{|c|}{$\begin{array}{l}\text { Mean age of caregiver of elderly psychiatric patients: } 44.3 \pm 10.2 \text { years } \\
\text { Mean age of caregiver of elderly medical patients: } 48.5 \pm 11.03 \text { years }\end{array}$} \\
\hline Sex & & & & & \multirow{3}{*}{1.684} & \multirow{3}{*}{1} & \multirow{3}{*}{0.194} \\
\hline Male & 27 & 45 & 11 & 16 & & & \\
\hline Female & 33 & 55 & 19 & 14 & & & \\
\hline \multicolumn{5}{|l|}{ Marital status } & \multirow[b]{3}{*}{0.089} & \multirow[b]{3}{*}{1} & \multirow[b]{3}{*}{0.766} \\
\hline Single & 45 & 75 & 23 & 22 & & & \\
\hline Married & 15 & 25 & 7 & 8 & & & \\
\hline \multicolumn{5}{|l|}{ Relationship } & \multirow{6}{*}{4.429} & \multirow{6}{*}{5} & \multirow{6}{*}{0.489} \\
\hline Spouse & 16 & 26.66 & 8 & 8 & & & \\
\hline Son & 21 & 35 & 9 & 12 & & & \\
\hline Daughter & 5 & 8.33 & 4 & 1 & & & \\
\hline Sibling & 4 & 6.66 & 1 & 3 & & & \\
\hline Daughter in law & 9 & 15 & 6 & 3 & & & \\
\hline Distant relation & 5 & 8.33 & 2 & 3 & & & \\
\hline \multicolumn{5}{|l|}{ Educational status } & \multirow{7}{*}{2.644} & \multirow{7}{*}{5} & \multirow{7}{*}{0.755} \\
\hline Illiterate & 12 & 20 & 5 & 7 & & & \\
\hline Primary & 14 & 23.33 & 7 & 7 & & & \\
\hline secondary & 18 & 30 & 9 & 9 & & & \\
\hline middle & 9 & 15 & 4 & 5 & & & \\
\hline $\begin{array}{l}\text { Intermediate/high } \\
\text { school }\end{array}$ & 5 & 8.33 & 3 & 2 & & & \\
\hline Graduate/postgraduate & 2 & 3.33 & 2 & 0 & & & \\
\hline \multicolumn{5}{|l|}{ 0ccupatinal status } & & & \\
\hline Unemployed worker & 7 & 11.66 & 4 & 3 & & & \\
\hline Unskilled worker & 13 & 21.66 & 6 & 7 & & & \\
\hline Semi skilled worker & 12 & 20 & 5 & 7 & & & \\
\hline
\end{tabular}




\begin{tabular}{|c|c|c|c|c|c|c|c|}
\hline Skilled worker & 12 & 20 & 6 & 6 & \multirow[t]{4}{*}{2.864} & \multirow[t]{4}{*}{6} & \multirow[t]{4}{*}{0.826} \\
\hline $\begin{array}{l}\text { Clerical, shop owner, } \\
\text { farmer }\end{array}$ & 9 & 15 & 4 & 5 & & & \\
\hline Semi-professional & 5 & 8.33 & 3 & 2 & & & \\
\hline professional & 2 & 3.33 & 2 & 0 & & & \\
\hline \multicolumn{5}{|l|}{ Income } & \multirow{8}{*}{0.952} & \multirow{8}{*}{6} & \multirow{8}{*}{0.987} \\
\hline$<979$ & 2 & 3.33 & 1 & 1 & & & \\
\hline $980-2935$ & 4 & 6.66 & 2 & 2 & & & \\
\hline $2936-4893$ & 8 & 13.2 & 4 & 4 & & & \\
\hline $4894-7322$ & 16 & 26.4 & 8 & 8 & & & \\
\hline $7323-9787$ & 14 & 23.33 & 6 & 8 & & & \\
\hline $9788-19574$ & 10 & 16.66 & 5 & 5 & & & \\
\hline$>19575$ & 6 & 10 & 4 & 2 & & & \\
\hline
\end{tabular}

* Significant at 0.05 level, $* *$ Significant at 0.01 level, $* * *$ Significant at 0.001 level

Table 3: Independent t-test of socio-demographic characteristics of caregivers

\begin{tabular}{|l|c|c|c|c|c|c|}
\hline \multirow{2}{*}{} & $\mathrm{N}$ & \multicolumn{2}{|c|}{ illness } & T value & Df & $\mathrm{p}$-value \\
\cline { 3 - 4 } & & Psychiatric & Medical & & & \\
\hline Age caregiver (years) & 30 & $44.3 \pm 10.2$ & $48.5 \pm 11.03$ & -1.534 & 58 & 0.130 \\
\hline Monthly Income caregiver (Rs) & 30 & $8920.0 \pm 6496.8$ & $8283 \pm 5319.8$ & 0.415 & 58 & 0.679 \\
\hline Caregiver duration (years) & 30 & $5.86 \pm 4.7$ & $6.36 \pm 4.66$ & -.414 & 58 & 0.680 \\
\hline
\end{tabular}

* Significant at 0.05 level , $* *$ Significant at 0.01 level ,*** Significant at 0.001 level

Table 4: Independent t-test of CBS, GHQ-30 \& WHO-QOL BREF

\begin{tabular}{|l|c|c|c|c|c|c|}
\hline & & Psychiatric $(\mathrm{N}=30)$ & Medical $(\mathrm{N}=30)$ & $\mathrm{t}$-value & $\mathrm{df}$ & $\mathrm{p}$-value \\
\hline Caregiver burden scale & 60 & $50.3 \pm 12.84$ & $36.2 \pm 10.67$ & 4.636 & 58 & $0.000^{* * *}$ \\
\hline GHQ -30 caregiver & 60 & $45.5 \pm 11.4$ & $32.8 \pm 9.05$ & 4.778 & 58 & $0.000^{* * *}$ \\
\hline WHOQOL -BREF caregiver & 60 & $80.1 \pm 6.6$ & $99.9 \pm 5.97$ & -12.200 & 58 & $0.000^{* * *}$ \\
\hline
\end{tabular}

*Significant at 0.05 level,$* *$ Significant at 0.01 level,*** Significant at 0.001 level

Table 5: Comparison of caregiver burden in male and female caregivers

\begin{tabular}{|l|c|c|c|c|c|c|}
\hline \multirow{2}{*}{} & & \multicolumn{2}{|c|}{ Sex } & t- value & df & p-value \\
\cline { 3 - 5 } & & Male & Female & & & \\
\hline \multirow{2}{*}{$\begin{array}{l}\text { caregiver burden } \\
\text { score }\end{array}$} & Psychiatric & $45.3 \pm 13.1$ & $53.2 \pm 12.06$ & -1.694 & 28 & .101 \\
\cline { 2 - 7 } & medical & $35.6 \pm 11.86$ & $36.8 \pm 9.53$ & -0.310 & 28 & 0.759 \\
\hline
\end{tabular}

Table 6: Zarit's caregiver burden inventory

\begin{tabular}{|c|c|c|c|c|c|}
\hline Severity & $\begin{array}{l}\text { Caregiver Elderly } \\
\text { Psychiatric }\end{array}$ & $\begin{array}{c}\text { Caregiver } \\
\text { Elderly Medical }\end{array}$ & Chi-square & df & p-value \\
\hline No/minimal burden $(0-20)$ & 0 & 2 & \multirow{4}{*}{15.237} & \multirow{4}{*}{3} & \multirow{4}{*}{$0.002 * *$} \\
\hline Mild to moderate (21-40) & 8 & 18 & & & \\
\hline Moderate to severe(41-60) & 13 & 10 & & & \\
\hline Severe $(61-88)$ & 9 & 0 & & & \\
\hline
\end{tabular}

Table 7: Correlation of various parameters in both group of caregivers

\begin{tabular}{|l|c|c|c|c|c|c|c|c|}
\hline & Illness & $\begin{array}{c}\text { Age } \\
\text { caregiver }\end{array}$ & $\begin{array}{c}\text { Income } \\
\text { caregiver }\end{array}$ & $\begin{array}{c}\text { GHQ } \\
\text { caregiver }\end{array}$ & $\begin{array}{c}\text { WHOQOL } \\
\text { caregiver }\end{array}$ & $\begin{array}{c}\text { Caregiver } \\
\text { duration }\end{array}$ & $\begin{array}{c}\text { GHQ } \\
\text { elderly }\end{array}$ & $\begin{array}{c}\text { WHO- } \\
\text { QOL } \\
\text { elderly }\end{array}$ \\
\hline $\begin{array}{l}\text { Caregiver } \\
\text { burden } \\
\text { scale }\end{array}$ & Psychiatric & $0.974^{* *}$ & $-0.924^{* *}$ & $0.992^{* *}$ & $-0.981^{* *}$ & $0.966^{* *}$ & $0.975^{* *}$ & $-0.978^{* *}$ \\
\cline { 2 - 8 } & Medical & $0.982^{* *}$ & $-0.919^{* *}$ & $0.989^{* *}$ & $-0.992^{* *}$ & $0.979^{* *}$ & $0.960^{* *}$ & $-0.992^{* *}$ \\
\hline
\end{tabular}

*Correlation is significant at 0.05 level, $* *$ Correlation is significant at 0.01 level

***Correlation is significant at 0.001 level 


\section{Discussion}

A total of 60 caregivers of elderly psychiatric and medical patients were enrolled in the study. Most of the caregivers in our study are family members, sons, spouses, daughters and daughter-in-law, as is the trend in most of the non western countries including India ${ }^{20,21,22}$. Females constituted the major fraction of this $(55 \%)$. Our study failed to find any significant difference in the burden between male and female caregivers, consistent with previous reports ${ }^{23,24}$. In the present study, burden on the caregivers of elderly psychiatric patients is found to be significantly higher as compared to caregivers of elderly medical patients. Several previous studies have also presented with similar results ${ }^{4,25-27}$, and have considered the possibility that this might be because of inappropriate and bizarre behaviors (disturbed sleep cycle, mood swings, abusive behavior, aggressive and violent outbursts etc) demonstrated by psychiatric patients, along with an inability to understand the sacrifices and troubles of their caregivers ${ }^{4,24}$.

In our participants, burden on caregivers was found to increase with a corresponding increase in their age, and is consistent with the several previous studies ${ }^{4,23,28}$. With increasing age, there is an increase in caregiver vulnerability and a consequent reduction in their ability to cope with mental and physical stresses ${ }^{4}$. Therefore, an increasing age might act as a negative factor in determining the wellness of these caregivers. In the present study, burden on both the caregivers of elderly medical and psychiatric patients was found to positively correlate with care giving duration. This is a controversial area, and the evidence regarding this is inconclusive. While several previous studies ${ }^{29-31}$ agree with this finding of ours, there is also evidence which state that there might be no such association with duration ${ }^{25}$, or that this burden on caregiver might be biphasic, increasing with duration of illness during the initial part and then, as the caregivers adjusted to their new lifestyle, reducing subsequently ${ }^{23}$. We believe that this latter observation might be made in prospective studies, and present methodology lacked this design.

General health and quality of life of caregivers of elderly psychiatric patients was found to be poorer than that of caregivers of elderly medical patients; and ZBI score showed positive and negative correlation with GHQ-30 and WHO-QOL scores (for both caregivers and elderly patients) respectively. These findings suggest that social, personal and occupational worsening of elderly patient negatively might reflect on the caregivers and deteriorate their perceived general health and quality of life and responsible for more severe caregiver burden.

\section{Conclusion}

Burden on caregivers of elderly psychiatric patients is significantly higher than that of caregivers of elderly medical patients. Age of caregiver and duration of care giving are important determinants of burden in both elderly medically ill and psychiatric patients, although here is no significant difference in burden between male and female caregivers. In a country like India where family members are the major caregivers of the elderly patients it is important to identify the needs of caregivers before it hampers the efficiency of the caregiver and provide suitable interventions to reduce the burden and improve quality of life of both caregiver and patient.

\section{Limitations}

Small sample size

Type of medical or psychiatric illness not considered

Cross sectional study without follow up data

\section{References}

1. World Health Organization. 10 facts on ageing and the life course, 2011. Available from: http://www.who.int/ features/ factfiles/ageing/en/

2. Census of India (2001) Population Projection for India and States 2001-2026 
(revised December 2006), Report of the technical group on population projections constituted by the National Commission on Population, May2006.

3. http://ghdx.healthmetricsandevaluation.org /global-burden-disease-study-2010-gbd2010-data-downloads

4. Ampalam P, Gunturu S, Padma V. A comparative study of caregiver burden in psychiatric illness and chronic medical illness. Indian J Psychiatry:2012 Jul-Sep; 54:3;239-24.

5. Zarit SH, Reever KE, Bach S. Relatives of the impaired elderly: Correlates of feeling of burden. The Gerontologist 1980; 20: 649-55.

6. Zarit SH, Todd PA, Zarit JM. Subjective burden of husbands and wives as caregivers: A longitudinal study. The Gerontologist 1986; 26: 260-6.

7. Krupnik Y, Pilling S, Killaspy H, Dalton J. A study of family contact with clients and staff of community mental health teams.Psychiatric Bull. 2005;29:174-6.

8. Aneshensel C, Pearlin L, Mullan J, Zarit S, Whitlatch C. Profiles in care giving: The unexpected career. San Diego, CA, US, Academic Press : 1995.

9. Gilleard CJ, Gilleard K, Gledhill K, Whittick J. Caring for the mentally infirm at home: A survey of the supporters. Journal of Epidemiology and Community Health1984;38: 319-325.

10. Teri L, Truax P, LogsdonR, Uomoto J, Zarit S, Vitaliano P. Assessment of behavioral problems in dementia: The revised Memory and Behavior Problems Checklist, in: Psychology and Aging. 1992; 7: 622-631.

11. Serrano-Aguilar PG, Lopez-Bastida J, Yanes-Lopez V. Impact on health-related quality of life and perceived burden ofinformal caregivers of individuals with Alzheimer's disease. Neuroepidemiology 2006:27(3);136-142.
12. Papastavrou E, Kalokerinou A, Papacostas SS, Tsangari H, Sourtzi P. Caring for a relative with dementia: family caregiver burden. Journal of Advanced Nursing.2007:58(5);446-457.

13. Kim H, Chang M, Rose K, Kim S. Predictors of caregiver burdenin caregivers of individuals with dementia. Journal of Advanced Nursing.2012:68(4);846-855.

14. Daniel WL. Effect of Financial Costs on Care giving Burden of Family Caregivers of Older Adults, SAGE Open .2012: October-December; $1-14$

15. Novak M, Guest C. Application of a multidimensional caregiver burden inventtory. Gerontologist.1989;29:798-803.

16. Baumgarten M, Hanley JA, Infante-Rivard C, Battista RN, Becker R, Gauthier S. Health of family members caring for elderly persons with dementia. Ann Intern Med. 1994;120:126-32.

17. Dunkin JJ, Anderson-Hanley C. Dementia caregiver burden: a review of the literature and guidelines for assessment and intervention. Neurology.1998;51(suppl 1): S53-S60.

18. Drinka TJ, Smith JC, Drinka PJ.Correlates of depression and burden for informal caregivers of patients in a geriatrics referral clinic. J Am GeriatrSoc. 1987;35:522-5.

19. WHOQOL Group. Development of the World Health Organization WHOQOLBREF quality of life assessment. Psychological Medicine 1998; 28:551-558.

20. Goldberg DP. Manual of the General Health Questionnaire. Windsor, England: NFER Publishing, 1978

21. Zarit S.H., Reever K.E., Bach-Peterson J. (1980). Relatives of the impaired elderly: correlated of feelings of burden. Gerontologist, 20, 649-655.

22. Chadda RK. Caring for the family caregivers of persons with mental illness.Indian J Psychiatry2014;56 :221-7. 
23. Karlıkaya G, Yüksel G, Varlıbas F, Tireli H. Caregiver burden indementia: a study in the Turkish population. The Internet J. Neurol. 2005:4 (2).

24. Christofoletti G, Oliani MM, BuckenGobbi LT, Gobbi S, Beinotti F,Stella F. Physical activity attenuates neuropsychiatric disturbances and caregiver burden in patients with dementia. Clinics.2011;66(4):613-618.

25. Prasanth A, Padma V, Raju NN, Narasimha Reddy M. A comparative study of caregiver burden in psychiatric illness \& chronic medical illness.AP J Psychol Med. 2010; Aug-Dec 11:16-20.

26. Gupta A, Sharma R. Burden and coping of caregivers of physical and mental illness. Delhi journal of psychiatry.Vol 16 no.2

27. Karlikaya G,Yukse G, Varlibas F, Tireli H. Caregiver burden in dementia: A study in the Turkish population. The Internet $\mathrm{J}$ Neurology.2005;4:2.

28. Chou KR, Chu H, Tseng CL, Lu RB. The measurement of caregiver burden. $\mathrm{J}$ Med Sci. 2003;23:73-82.

29. Ganguly KK, CHadda RK, Singh TB. Caregiver Burden and Coping in Schizophrenia and Bipolar Disorder. The American Journal of Psychiatry. 2010 Apr;161(5):850-856.

30. Gupta R,Pillai V K. Elder Caregiving in South-Asian Families in the United States and India. Social Work \& Society.2012:10;2.

31. Grad J, Sainsbury P. The effect that patientshave on their family in community care andcontrol psychiatric services: A two years followup. Br J Psychiatry 1968; 39: 265-278.
32. Hoeinig J, Hamilton MW. The schizophrenic patient in the community and his effect on the household. International J Soc Psychiatry, 1966;12: 165-176.

33. Jones SL, Roth D, Jones PK. Effect of demographic and behavioral variables on burden ofcaregivers of chronic mentally ill persons. Psychiatr Serv 1995; 46: 141-145. 